Article

\title{
4-Aminobenzoic Acid-Coated Maghemite Nanoparticles as Potential Anticancer Drug Magnetic Carriers: A Case Study on Highly Cytotoxic Cisplatin-Like Complexes Involving 7-Azaindoles
}

\section{Pavel Štarha ${ }^{1}$, Martin Stavárek ${ }^{1}$, Jiří Tuček ${ }^{2}$ and Zdeněk Trávníček ${ }^{1, *}$}

1 Regional Centre of Advanced Technologies and Materials, Department of Inorganic Chemistry, Faculty of Science, Palacký University, 17. listopadu 12, Olomouc CZ 77146, Czech Republic; E-Mails: pavel.starha@upol.cz (P.Š.); martin.stavarek01@upol.cz (M.S.)

2 Regional Centre of Advanced Technologies and Materials, Department of Experimental Physics, Faculty of Science, Palacký University, 17. listopadu 12, Olomouc CZ 77146, Czech Republic; E-Mail: jiri.tucek@upol.cz

* Author to whom correspondence should be addressed; E-Mail: zdenek.travnicek@upol.cz Tel.: +420-585-634-352; Fax: +420-585-634-954.

Received: 23 December 2013; in revised form: 17 January 2014 / Accepted: 23 January 2014 / Published: 28 January 2014

\begin{abstract}
This study describes a one-pot synthesis of superparamagnetic maghemite-based 4-aminobenzoic acid-coated spherical core-shell nanoparticles (PABA@FeNPs) as suitable nanocomposites potentially usable as magnetic carriers for drug delivery. The PABA@FeNPs system was subsequently functionalized by the activated species $\left(1^{*}\right.$ and $\left.2^{*}\right)$ of highly in vitro cytotoxic cis-[ $\left.\mathrm{PtCl}_{2}(3 \mathrm{Claza})_{2}\right](\mathbf{1} ; 3 \mathrm{Claza}$ stands for 3 -chloro7-azaindole) or cis-[ $\left.\mathrm{PtCl}_{2}(5 \mathrm{Braza})_{2}\right]$ (2; 5Braza stands for 5-bromo-7-azaindole), which were prepared by a silver(I) ion assisted dechlorination of the parent dichlorido complexes. The products 1*@PABA@FeNPs and 2*@PABA@FeNPs, as well as an intermediate PABA@FeNPs, were characterized by a combination of various techniques, such as Mössbauer, FTIR and EDS spectroscopy, thermal analysis, SEM and TEM. The results showed that the products consist of well-dispersed maghemite-based nanoparticles of $13 \mathrm{~nm}$ average size that represent an easily obtainable system for delivery of highly cytotoxic cisplatin-like complexes in oncological practice.
\end{abstract}


Keywords: maghemite; nanoparticles; magnetic; platinum complexes; 7-azaindole derivatives; drug delivery

\section{Introduction}

The platinum(II) complexes, such as cisplatin, oxaliplatin or carboplatin, are well-established anticancer chemotherapeutics used worldwide for the treatment of various types of cancer [1]. Application of these drugs causes several negative side-effects, such as nephrotoxicity, neurotoxicity or myelosuppression, which represent a permanent incentive for bioinorganic chemists to find novel non-platinum drugs (e.g., ruthenium complexes) or platinum complexes with diminished side-effects or to study the possibilities of the targeted drug delivery of the known as well as novel cytotoxic platinum complexes to the tumour tissues. The latter option, i.e., targeted drug delivery, offers various approaches, as reviewed e.g., in [2-4]. One of them is based on the use of magnetic nanoparticles (NPs) coated with a suitable shell, comprising e.g., organic molecules of the same entity, that is able to interact with the drug $[5,6]$. A distribution of such systems within the organism suffering with cancer could be affected by an external magnetic field, whose application concentrates the drug into the tumour tissue.

Among all the magnetic nanoparticles of transition metals and their oxides, iron oxide-based nanosystems hold a paramount position in various medical fields due to their promising properties including magnetic (e.g., superparamagnetism, strong magnetic response and saturation under small applied magnetic fields, excellent heating performance in the frequencies of the alternating magnetic field safe for humans) and biochemical (e.g., very low toxicity, biocompatibility, biodegradability) features $[7,8]$. To date, they have been successfully employed as negative contrast agents in magnetic resonance imaging, for cell labelling and separation, drug delivery, and as functional components in magnetically-assisted hyperthermia for cancer treatment. Once iron oxide nanoparticles are functionalized with suitable bioactive substances, the resulting system then performs both the diagnostic and therapeutic actions, giving birth to a novel branch of medicine known as theranostics [9]. Many iron oxide-based (both maghemite or magnetite) nanocarriers designed and fabricated for magnetic drug delivery purposes have been reported in the literature to date, involving various synthetic approaches and the use of different organic-coating layers [5,6,10-19]. Regarding the nanocomposites with maghemite-based core-shell NPs functionalized with platinum-based drugs (i.e., structurally similar to those reported in this work), to the best of our knowledge only two such works have been reported to date. Both of them report maghemite-based NPs with dechlorinated cisplatin bound to 4-oxo-4-(3(triethoxysilyl)propylamino)butanoic acid (OTPBA) [20,21]. These systems showed remarkable, timedependent in vitro cytotoxicity against MCF7, HeLa, A549 and A549R human cancer cell lines, which is comparable with that of cisplatin after $72 \mathrm{~h}$, and moreover, they can be simultaneously used as MRI contrast agents. Several other works have dealt with similar magnetite-based NPs suitable for magnetic drug delivery and studied cisplatin as the model drug as follows: Deng and Lei reported the $\mathrm{Fe}_{3} \mathrm{O}_{4} / \mathrm{SiO}_{2}$ cores with PEG-PLA shell (PEG = polyethylene glycol, PLA = polylactic acid) and loaded cisplatin [22]. A similar system, but with a PLA shell, was studied by Devi et al., who focused on 
loading and release properties of cisplatin [23]. Ashjari et al. published the preparation of cisplatinfunctionalized magnetite NPs with biodegradable poly(lactic-co-glycolic acid) (PLGA) with different morphological properties of the resulting composite [24]. Several other studies focused on the analogical systems (magnetite core and cisplatin as the functionalizing agent) differing in organic shells, such as folate acid- [25], squalene- [26], carboxymethylcellulose- [27], dextrane- [28] or poly(ethyl-2-cyanoacrylate)- [29] based layer. Finally, Li et al. studied the effect of cisplatin-loaded magnetite-based NPs on multidrug resistance and its mechanism [30]. Although all of the mentioned nanosystems have to be considered as universal in terms of functionalization by the platinum complexes, it has to be noted that to the best of our knowledge only one work [31] has reported iron oxide-based NPs functionalized with platinum complexes other than the mentioned cisplatin. In particular, the magnetite-silica composite nanoparticles were investigated as carriers of a photoactive platinum diimine complex.

In an effort to research the possibilities of targeted delivery of the recently reported highly in vitro cytotoxic cisplatin-like complexes involving 7-azaindole derivatives investigated by our team [32-34], we developed a novel system based on easily obtainable magnetic nanoparticles. They consist of maghemite-based 4-aminobenzoic acid (PABA)-coated core-shell nanoparticles (PABA@FeNPs) functionalized by the activated (i.e., dechlorinated) platinum(II) complexes bearing various 7-azaindoles (the complexes $\mathbf{1}$ and $\mathbf{2}$, whose activated form is symbolized as $\mathbf{1}$; and $\mathbf{2 *}$; Figure 1a). The obtained systems 1*@PABA@FeNPs and 2*@PABA@FeNPs (Figure 1b) were thoroughly characterized by relevant techniques including Mössbauer and FTIR spectroscopy, simultaneous TG/DTA thermal analysis, transmission electron microscopy (TEM) and scanning electron microscopy (SEM) equipped with energy-dispersive X-ray spectroscopy (EDS). The resulting nanocomposites, which were found to be $13.0 \pm 2.1 \mathrm{~nm}$ of size with acceptable dispersibility, are of high potential from the magnetic drug delivery point of view.

Figure 1. (a) The structural formulas of highly cytotoxic cis-[ $\left.\mathrm{PtCl}_{2}(3 \mathrm{Claza})_{2}\right]$ $(\mathbf{1} ; 3$ Claza $=3$-chloro-7-azaindole $)$ and $c i s$ - $\left[\mathrm{PtCl}_{2}(5 \text { Braza })_{2}\right](2 ; 5$ Braza $=5$-bromo-7azaindole), and the corresponding activated diaqua species symbolized as $1 *$ and $2 *$ used for the interaction with PABA@FeNPs; (b) the proposed composition of the studied 1*@PABA@FeNPs and 2*@PABA@FeNPs based on the maghemite core coated with 4-aminobenzoic acid and functionalized with $1 *$ or $2^{*}$; and (c) photos of the obtained aqueous suspensions of PABA@FeNPs (up) and 2*@PABA@FeNPs (down) without (left) and with (right) an external magnetic field.

(a)

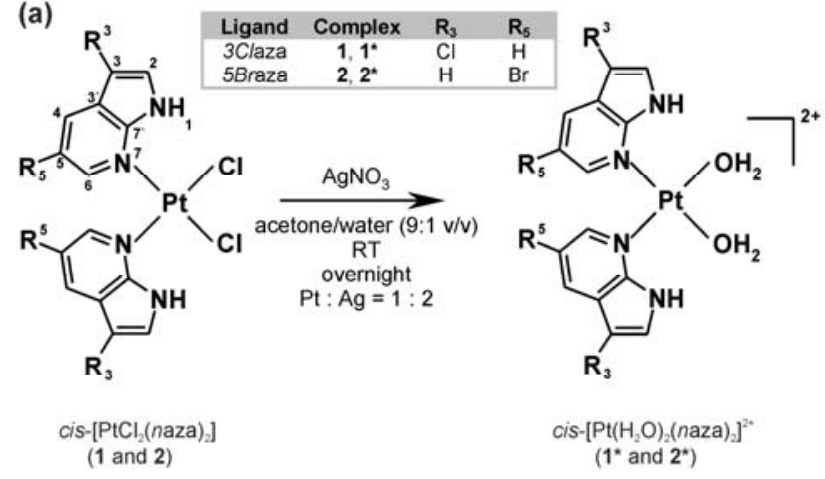

(b)

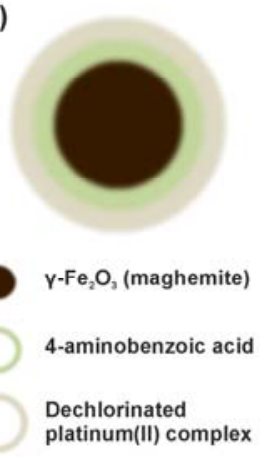

(c)

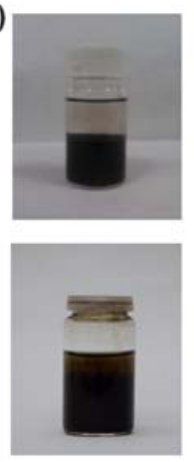

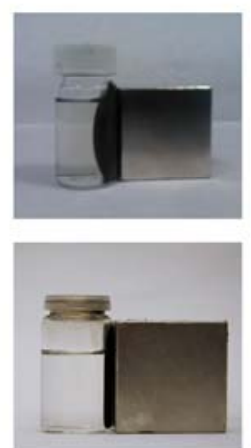




\section{Results and Discussion}

\subsection{Preparation and Properties of PABA@FeNPs}

The maghemite-based nanoparticles (FeNPs) coated with 4-aminobenzoic acid (PABA@FeNPs) were prepared be a method using a mixture of the $\mathrm{Fe}(\mathrm{III})$ and $\mathrm{Fe}(\mathrm{II})$ salts $\left(\mathrm{FeCl}_{3} \cdot 6 \mathrm{H}_{2} \mathrm{O}\right.$ and $\mathrm{FeCl}_{2} \cdot 4 \mathrm{H}_{2} \mathrm{O}$ in this work), which was mixed together with PABA in deionized water under atmospheric conditions. $\mathrm{NH}_{4} \mathrm{OH}$ was finally added to the mixture which resulted in the formation of the maghemite-based PABA@FeNPs nanoparticles. It has to be noted that the usual preparation of maghemite-based NPs involves magnetite NPs (prepared from the mixture of Fe(III) and Fe(II) salts under nitrogen [35,36]) and subsequently oxidized by e.g., diluted nitric acid [20,21]. Since we aimed to prepare maghemitebased NPs, we used a different approach — we did not perform the syntheses under nitrogen but under atmospheric conditions, which was found to be sufficient for the magnetite oxidation to occur without addition of any other oxidizing agent.

The presence of the organic layer coating the maghemite NPs within the obtained PABA@FeNPs was proved by the FTIR spectra recorded in the $400-4,000 \mathrm{~cm}^{-1}$ region (Figure 2 and Figure S1) as well as by the thermal analysis (Figure S2) [35,37]. The FTIR spectrum of PABA@FeNPs contained the characteristic peak of maghemite at $c a .550 \mathrm{~cm}^{-1}$ clearly assignable to the $v(\mathrm{Fe}-\mathrm{O})$ vibration, as well as a series of peaks, whose positions in the spectrum correlates with those of free PABA molecule (see Figure S1 and Experimental Section). The results of the FTIR spectroscopy also indirectly proved that PABA is bonded to $\gamma-\mathrm{Fe}_{2} \mathrm{O}_{3}$ within the PABA@FeNPs nanocomposite through the deprotonated carboxyl group, because there is only one major peak in the region characteristic for this functional group with a band centred at $1,603 \mathrm{~cm}^{-1}$, as compared with four in total peaks found in the spectrum of free PABA at 1,571, 1,597, 1,623 and $1,660 \mathrm{~cm}^{-1}$ (Figure S1).

Figure 2. FTIR spectra of the maghemite nanoparticles coated with 4-aminobenzoic acid (PABA@FeNPs; red line), the parent complex 2 involving 5-bromo-7-azaindole (blue line), and the resulting system with the activated complex $\left(2^{*}\right)$ bound on the maghemite nanoparticles coated with 4-aminobenzoic acid (2*@PABA@FeNPs).

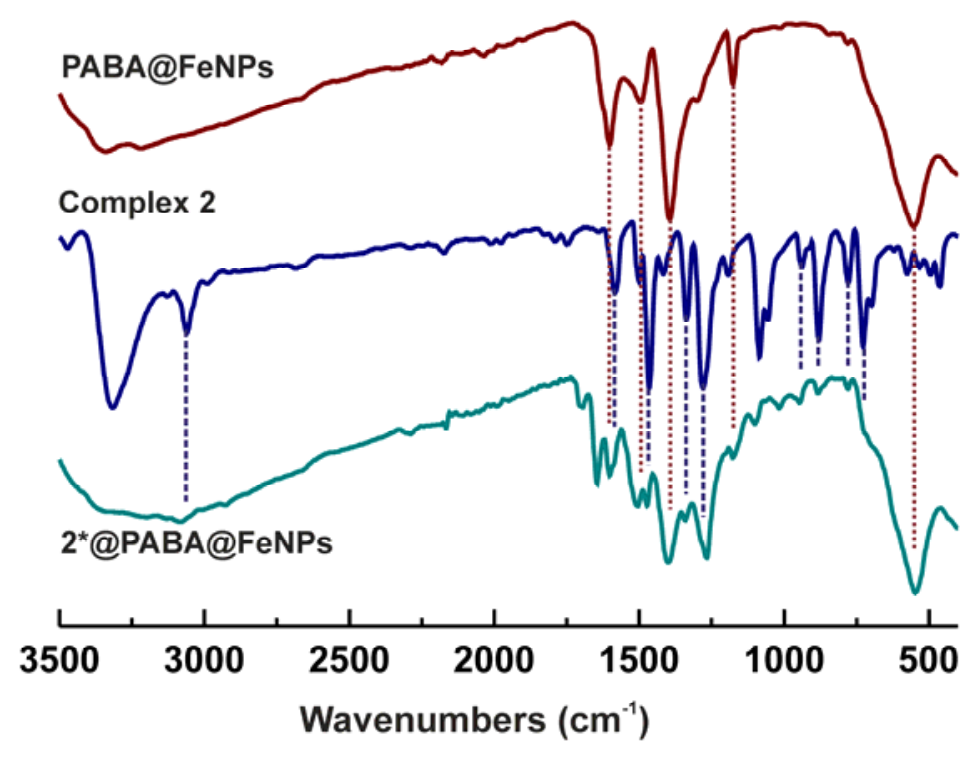


The PABA@FeNPs hybrid systems exhibited, as expected, a strong attraction to the magnetic field (Figure 1c) and good stability in solution (no macroscopic changes, e.g., colour or magnetism, after one weak of standing in the fridge) and in solid state (usable with no changes of their properties after more than two months of standing in the fridge).

\subsection{Functionalization of PABA@FeNPs by Platinum(II) Complexes}

We assumed a bonding of the platinum(II) complexes through Pt-N bonds formed between the $\mathrm{Pt}$ (II) atom of the activated species and the amino group of PABA. As previously reported, PABA with a substituted carboxyl group (which simulates the bonding of PABA to the maghemite NPs through the mentioned functional group) binds to platinum through the amino group [38-40]. Further, the X-ray structures of several platinum(II) complexes involving aniline or its variously substituted derivatives, such as 4-alkylanilines (e.g., [41,42]) are described in the literature. These facts proved PABA is a suitable coating agent for magnetic therapeutic/theranostic systems functionalized with platinum-based agents.

The initial cis-dichloridoplatinum(II) complexes of the composition cis-[ $\left.\mathrm{PtCl}_{2}(\text { naza })_{2}\right]$ (1 and 2), which were recently described in the literature by our team as having significant antitumor properties $[33,34]$, were activated by their reactions with a stoichiometric amount of silver(I) nitrate, resulting in dechlorination and formation of the diaquaplatinum(II) species cis- $\left[\mathrm{Pt}\left(\mathrm{H}_{2} \mathrm{O}\right)_{2}(3 \mathrm{Claza})_{2}\right]^{2+}$ $\left(1^{*}\right)$ and cis- $\left[\mathrm{Pt}\left(\mathrm{H}_{2} \mathrm{O}\right)_{2}(5 \mathrm{Braza})_{2}\right]^{2+}\left(2^{*}\right)$. The activated species, involving the labile $\mathrm{Pt}$-aqua bonds which represent suitable sites for consequent formation of the mentioned $\mathrm{Pt}-\mathrm{N}$ bonds with PABA, were allowed to interact in acetone with the PABA@FeNPs nanoparticles for $48 \mathrm{~h}$. The final systems (1*@PABA@FeNPs and 2*@PABA@FeNPs), which showed strong attraction to the external magnetic field (Figure 1c), were magnetically isolated, purified and stored in the fridge. The presence of the platinum(II) species within the obtained maghemite-based nanocomposite was proved by FTIR spectroscopy (Figure 2) as well as by EDS spectroscopy (Figure 3f). FTIR spectroscopic experiments were performed with the aim to better characterize the studied systems. The detailed analysis of FTIR spectra revealed that bands observed in the spectrum of 1*@PABA@FeNPs at 785, 1,018, 1,099, 1,277, 1,338, 1,516, 1,602, 2,906 and 3,107 $\mathrm{cm}^{-1}$ and in the spectrum of 2*@PABA@FeNPs at 700, 883 , 946, 1,267, 1,341, 1,473, 1,603 and 3,082 $\mathrm{cm}^{-1}$ were not detected in the spectrum of the PABA@FeNPs system. Moreover, the positions of these bands correlate well with those detected in the spectra of the complexes 1 and 2 (Figure 2 for the complex 2 and 2*@PABA@FeNPs), thus showing on the presence of the platinum(II) 7-azaindole species within the resulting nanocomposites. An interpretation of the far-FTIR spectra recorded at $150-600 \mathrm{~cm}^{-1}$ provides indirect proof of the covalent bonding between the platinum(II) species and PABA@FeNPs within the studied nanosystems 1*@PABA@FeNPs and 2*@PABA@FeNPs. In particular, the performed far-FTIR experiments regarding 2, 2* and 2*@PABA@FeNPs indicated changes in inner coordination spheres in the vicinity of the central platinum(II) atom, i.e., the changes going from a $\mathrm{PtCl}_{2} \mathrm{~N}_{2}$ donor set (the starting complex 2; two $v(\mathrm{Pt}-\mathrm{Cl})$ maxima at 336 and $345 \mathrm{~cm}^{-1}$ ), through a $\mathrm{PtN}_{2} \mathrm{O}_{2}$ donor set (the dechlorinated complex $2 *$; two $v(\mathrm{Pt}-\mathrm{O})$ maxima at 322 and $332 \mathrm{~cm}^{-1}$ ) to a $\mathrm{PtN}_{4}$ one (the resulting system 2*@PABA@FeNPs; no bands detected in the region mentioned for both the $v(\mathrm{Pt}-\mathrm{Cl})$ or $v(\mathrm{Pt}-\mathrm{O})$ vibrations $)$, as depicted in Figure S3. In other words, although we did not detect the vibrations connected with the anticipated 
Pt-N bonds between the platinum(II) species and amino group of PABA, we assume that these vibrations are overlapped (analogically to those at $c a 520 \mathrm{~cm}^{-1}$ assignable to Pt-N bonds between the central $\mathrm{Pt}(\mathrm{II})$ atom and 7-azaindole rings) by a wide and intensive band belonging to $v(\mathrm{Fe}-\mathrm{O})$. The $v(\mathrm{Fe}-\mathrm{O})$ vibration was, together with a band centred at $579 \mathrm{~cm}^{-1}$ assignable to the vibrations connected with the deformation of the 7-azaindole moiety [43], the only band detected in the discussed far-FTIR spectrum of 2*@PABA@FeNPs.TEM images of the prepared 1*@PABA@FeNPs and 2*@PABA@FeNPs systems provided the relevant information regarding the shape, size, and uniformity of the resulting NPs (Figures 3a,b). The systems were found to be spherical, core-shell well-dispersed composites with an average size of $13.0 \pm 2.1 \mathrm{~nm}$. SEM was used to investigate the surface morphology of the prepared maghemite-based NPs (Figure 3c,e). A comparison of the SEM images depicted for PABA@FeNPs (Figure 3c) and 2*@PABA@FeNPs (Figure 3e) did not show any noticeable difference between their properties, since both systems were detected by SEM (as well as by the above-mentioned TEM) as having a spherical shape of individual NPs, which agglomerated together to the structure without any specific shape.

Figure 3. TEM images of 2*@PABA@FeNPs $\{$ (a) with $100 \mathrm{~nm}$ resolution and (b) with $50 \mathrm{~nm}$ resolution $\},$ SEM images of PABA@FeNPs (c) and 2*@PABA@FeNPs (e) given with their EDS patterns (d, f).
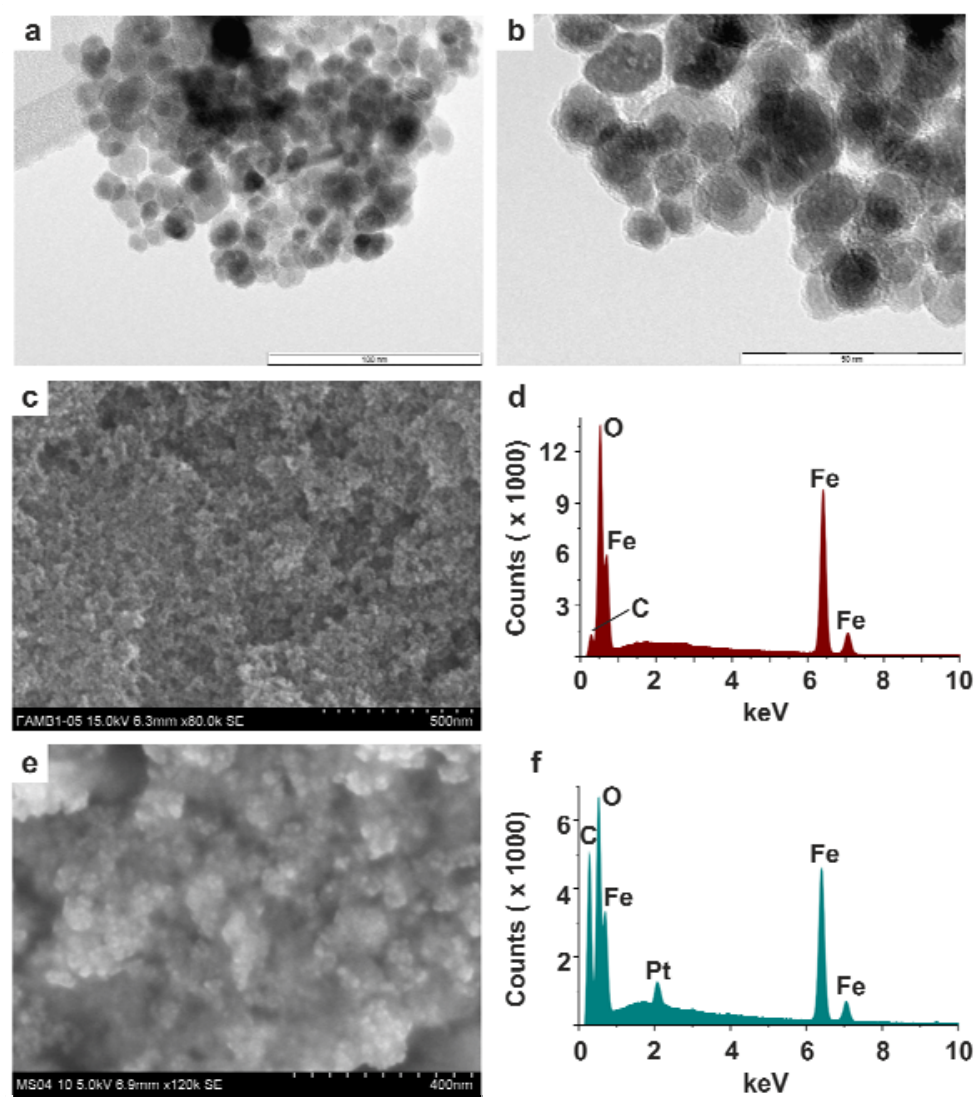

Simultaneous TG/DTA thermal analysis revealed a considerable difference between the weight losses of PABA@FeNPs and those involving functionalized platinum(II) complexes (represented by 2*@PABA@FeNPs; Figure S2).PABA@FeNPs did not show any weight increase in the 100-150 ${ }^{\circ} \mathrm{C}$ range (after the loss of water physically adsorbed on the the prepared NPs), which is known to be 
connected with an oxidation of $\mathrm{Fe}^{2+}$ ions, which indirectly proved the chemical composition of the magnetic core (maghemite). The PABA@FeNPs system was thermally stable between 114 and 148 ${ }^{\circ} \mathrm{C}$, when its thermal degradation (connected with an oxidation of the organic layer coating the maghemite core) started and continued to $460{ }^{\circ} \mathrm{C}$ (total weight loss equals $8.0 \%$ ). The product of the thermal decomposition, most probably $\gamma-\mathrm{Fe}_{2} \mathrm{O}_{3}$ as previosly reported for maghemite NPs [44], did not show any weight change up to $530^{\circ} \mathrm{C}$, however, an exothermic effect unambiguously assignable to the $\gamma-\mathrm{Fe}_{2} \mathrm{O}_{3}$ to $\alpha-\mathrm{Fe}_{2} \mathrm{O}_{3}$ conversion was detected on the DTA curve with the maximum at $488{ }^{\circ} \mathrm{C}$ (Figure S2). A considerably different weight loss (19.8\%) as well as TG-curve shape (a continual decomposition) was found for 2*@PABA@FeNPs indirectly proving the presence of the platinum(II) species within the resulting system (Figure $\mathrm{S} 2$ ).

\subsection{Mössbauer Spectroscopy}

The ${ }^{57} \mathrm{Fe}$ Mössbauer spectra of the samples studied are depicted in Figure 4, while the values of the Mössbauer hyperfine parameters, derived from the fitting of the recorded Mössbauer spectra, are listed in Table 1.

Figure 4. Room-temperature Mössbauer spectra of (a) PABA@FeNPs and (b) 2*@PABA@FeNPs; doublet - assigned to the $\mathrm{Fe}^{3+}$ relaxation component, singlet - asigned to the $\mathrm{Fe}^{3+}$ superparamagnetic component.
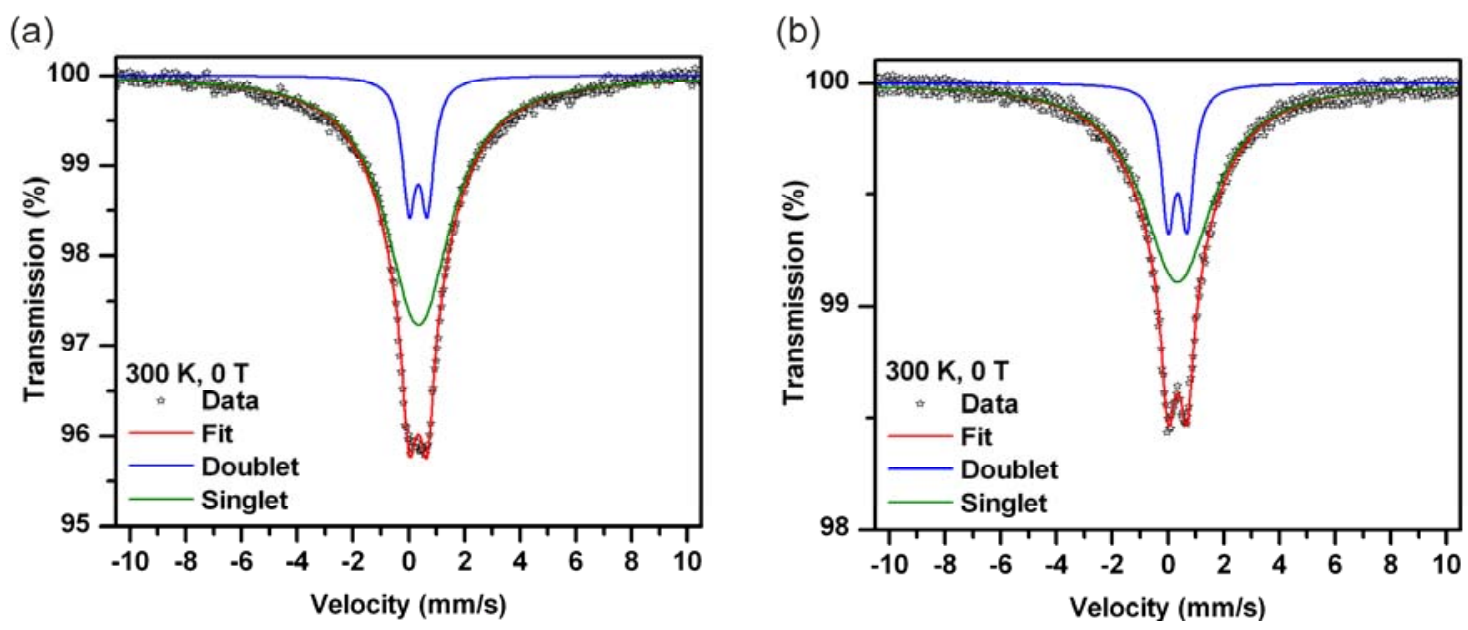

Table 1. Values of the Mössbauer hyperfine parameters, derived from the fitting of the room-temperature Mössbauer spectra of PABA@FeNPs and 2*@PABA@FeNPs, where $\delta$ is the isomer shift, $\Delta E_{Q}$ is the quadrupole splitting and RA is the spectral area of the individual spectral components.

\begin{tabular}{cccccl}
\hline Sample & Component & $\begin{array}{c}\boldsymbol{\delta} \pm \mathbf{0 . 0 1} \\
(\mathbf{m m} / \mathbf{s})\end{array}$ & $\begin{array}{c}\Delta \boldsymbol{E}_{\boldsymbol{Q}} \pm \mathbf{0 . 0 1} \\
(\mathbf{m m} / \mathbf{s})\end{array}$ & $\begin{array}{c}\mathbf{R A} \pm \mathbf{1} \\
\mathbf{( \% )}\end{array}$ & Assignment \\
\hline PABA@FeNPs & Doublet & 0.34 & 0.66 & 18 & $\begin{array}{l}\mathrm{Fe}^{3+} \text { relaxation component } \\
\end{array}$ \\
& Singlet & 0.35 & & 82 & $\begin{array}{l}\mathrm{Fe}^{3+} \text { superparamagnetic } \\
\text { component }\end{array}$ \\
2 2*PABA@FeNPs & Doublet & 0.35 & 0.69 & 88 & $\begin{array}{l}\mathrm{Fe}^{3+} \text { relaxation component } \\
\mathrm{Fe}^{3+} \text { superparamagnetic } \\
\text { component }\end{array}$ \\
& Singlet & 0.35 & & 78 &
\end{tabular}


The room-temperature Mössbauer spectrum of both the PABA@FeNPs and 2*@PABA@FeNPs sample shows only relaxation components (i.e., singlet and doublet, see Figures 4a,b, respectively) with the values of the Mössbauer hyperfine parameters (see Table 1) typical of high-spin Fe(III) atom in iron(III) oxides [45]; there is no indication of presence of the $\mathrm{Fe}^{2+}$ valence state. Thus, the nanoparticles in both samples are solely of $-\mathrm{Fe}_{2} \mathrm{O}_{3}$ origin. This is expected in connection with their small size with a large surface area securing their complete oxidation. On the timescale of the Mössbauer technique, all the nanoparticles in both assemblies behave in a superparamagnetic manner at room temperature. The doublet component belongs to the nanoparticles with thermally fluctuating superspins having relaxation times much smaller than the characteristic measurement time $\left(\tau_{\mathrm{m}}\right)$ of the Mössbauer spectroscopy, while the presence of a singlet corresponds to those nanoparticles the superspin of which thermally fluctuates between the energetically favored orientations with a relaxation time close to $\tau_{\mathrm{m}}$. The PABA@FeNPs and 2*@PABA@FeNPs systems would show superparamagnetic features in the magnetization measurements at room temperature, however, their magnetic characteristics will be significantly driven by finite-size and surface effects (manifested, for example, by a smaller saturation magnetization or lack of saturation and reduced magnetic response under small applied magnetic fields).

\section{Experimental}

\subsection{Materials and Methods}

The starting materials $\mathrm{K}_{2}\left[\mathrm{PtCl}_{4}\right]$, 3-chloro-7-azaindole (3Claza), 5-bromo-7-azaindole (5Braza), iron(III) chloride hexahydrate $\left(\mathrm{FeCl}_{3} \cdot 6 \mathrm{H}_{2} \mathrm{O}\right)$, iron(II) chloride tetrahydrate $\left(\mathrm{FeCl}_{2} \cdot 4 \mathrm{H}_{2} \mathrm{O}\right)$, $p$-aminobenzoic acid (PABA), 25\% $\mathrm{NH}_{4} \mathrm{OH}$, silver nitrate $\left(\mathrm{AgNO}_{3}\right)$ and solvents were supplied by Sigma-Aldrich Co. (Prague, CzechRepublic) and Acros Organics Co. (Pardubice, CzechRepublic), and used as received. The platinum(II) complexes cis-[ $\left.\mathrm{PtCl}_{2}(3 \mathrm{Claza})_{2}\right]$ (1) and cis-[ $\mathrm{PtCl}_{2}\left(5 \mathrm{Braza}_{2}\right]$ (2) (Figure 1a) were prepared as described in our recent paper [33].

Transmission electron microscopy (TEM) was carried out on a JEOL 2010 microscope (200 kV, $1.9 \AA$ point-to-point resolution). A drop of high-purity water with the ultrasonically dispersed samples was placed onto a holey-carbon film supported by a copper-mesh TEM grid and dried in air at room temperature. Scanning electron microscopy (SEM) was performed, together with energy-dispersive X-ray (EDS) spectroscopy, by a Hitachi 6600 FEG microscope (5-15 keV accelerating voltage; the dried samples were placed on an aluminum holder equipped with double-sided adhesive carbon tape). The ${ }^{57} \mathrm{Fe}$ Mössbauer spectra of the studied samples were recorded at room temperature employing a Mössbauer spectrometer operating at the constant acceleration mode and equipped with a $50 \mathrm{mCi}$ ${ }^{57} \mathrm{Co}(\mathrm{Rh})$ source. The isomer shift values are related to $\alpha$-Fe at room temperature. The Mössbauer spectra were fitted with the MossWinn software program; prior to fitting, the signal-to-noise ratio was enhanced by a statistically based algorithm [46]. Infrared spectra $\left(400-4000 \mathrm{~cm}^{-1}\right.$ and $150-600 \mathrm{~cm}^{-1}$ regions) were recorded on a Nexus 670 FT-IR (Thermo Nicolet, Waltham, MA, USA) using the ATR technique. Simultaneous thermogravimetric (TG) and differential thermal (DTA) analyses were performed using an Exstar TG/DTA 6200 thermal analyzer (Seiko Instruments Inc., Chiba, Japan) from room temperature to $650^{\circ} \mathrm{C}\left(5.0^{\circ} \mathrm{C} \mathrm{min}^{-1}\right)$ in dynamic air atmosphere $\left(50 \mathrm{~mL} \mathrm{~min}{ }^{-1}\right)$. 


\subsection{PABA@FeNPs Nanoparticles}

4-Aminobenzoic acid (PABA; $0.62 \mathrm{~g}, 4.5 \mathrm{mmol}$ ) was, due to its poor solubility at laboratory temperature, dissolved in hot $\left(80{ }^{\circ} \mathrm{C}\right)$ deionized water $(75 \mathrm{~mL})$ and then, $\mathrm{FeCl}_{3} \cdot 6 \mathrm{H}_{2} \mathrm{O}(1.17 \mathrm{~g}$; $4.3 \mathrm{mmol})$ dissolved in deionized water $(5 \mathrm{~mL})$ was added. The mixture was stirred at $80{ }^{\circ} \mathrm{C}$ for $30 \mathrm{~min}$ and then $\mathrm{FeCl}_{2} \cdot 4 \mathrm{H}_{2} \mathrm{O}(0.86 \mathrm{~g} ; 4.3 \mathrm{mmol})$ dissolved in deionized water $(2 \mathrm{~mL})$ was added to the solution. After $30 \mathrm{~min}$ of stirring at $80{ }^{\circ} \mathrm{C}$ the last reagent $\left(10 \mathrm{~mL}\right.$ of $\left.25 \% \mathrm{NH}_{4} \mathrm{OH}\right)$ was slowly added. The solution turned dark black as the PABA@FeNPs formed. The suspension was intensively stirred at $80{ }^{\circ} \mathrm{C}$ for $60 \mathrm{~min}$. Finally, nanoparticles were magnetically isolated and washed with deionized water $(3 \times 20 \mathrm{~mL})$ and acetone $(3 \times 20 \mathrm{~mL})$. Part of the final ferrofluid suspension of PABA@FeNPs (Figure 1c) was stored under degassed acetone in the fridge, while the rest of the product was dried with nitrogen gas and in desiccator over silica gel, and stored in the fridge. PABA@FeNPs: FTIR $\left(v_{\mathrm{ATR}} / \mathrm{cm}^{-1}\right)$ : 552vs, $783 \mathrm{w}, 1,179 \mathrm{~m}, 1,395 \mathrm{vs}, 1,493 \mathrm{~m}, 1,603 \mathrm{~s}, 3,219 \mathrm{~s}, 3,334 \mathrm{~s}$.

\subsection{Synthesis of 1*@PABA@FeNPs and2*@PABA@FeNPs}

The complexes 1 (110 mg; $0.2 \mathrm{mmol})$ and $\mathbf{2}(130 \mathrm{mg} ; 0.2 \mathrm{mmol})$ were dissolved in acetone (10 $\mathrm{mL})$ and two molar equivalents of $\mathrm{AgNO}_{3}$ dissolved in a minimum volume of deionized water were added. The mixture was stirred at laboratory temperature in the dark for $24 \mathrm{~h}$. After that, $\mathrm{AgCl}$ was removed by filtration and washed with acetone $(3 \times 1 \mathrm{~mL})$ to produce the filtrate containing the solution of the dechlorinated complexes of the composition cis- $\left[\mathrm{Pt}\left(\mathrm{H}_{2} \mathrm{O}\right)_{2}(3 \mathrm{Claza})_{2}\right]^{2+}\left(1^{*}\right)$, and cis- $\left[\mathrm{Pt}\left(\mathrm{H}_{2} \mathrm{O}\right)_{2}(5 \mathrm{Braza})_{2}\right]^{2+}\left(2^{*}\right)$ (Figure 1a). PABA@FeNPs $(0.5 \mathrm{~mL}$ of the acetone suspension involving $100 \mathrm{mg}$ of PABA@FeNPs) was poured in and the mixture was stirred for $48 \mathrm{~h}$ to produce the final systems 1*@PABA@FeNPs and 2*@PABA@FeNPs (Figures 1b,c). These products were magnetically isolated, washed with acetone $(3 \times 20 \mathrm{~mL})$, dried (nitrogen and then in desiccator over silica gel) and stored in the fridge.1*@PABA@FeNPs: FTIR $\left(v_{\mathrm{ATR}} / \mathrm{cm}^{-1}\right): 550 \mathrm{vs}, 785 \mathrm{w}, 1,018 \mathrm{~m}$, $1,099 \mathrm{w}, 1,179 \mathrm{~m}, 1,208 \mathrm{~m}, 1,277 \mathrm{~s}, 1,338 \mathrm{~s}, 1,398 \mathrm{vs}, 1,516 \mathrm{~m}, 1,602 \mathrm{~s}, 1,694 \mathrm{w}, 2,906 \mathrm{~s}, 3,107 \mathrm{~s}$. 2*@PABA@FeNPs: FTIR ( $\left.v_{\mathrm{ATR}} / \mathrm{cm}^{-1}\right)$ : 547vs, 700w, 883w, 946w, 1,017w, 1,101w, 1,177m, 1,267vs, 1,341s, 1,400vs, 1,473s, 1,500s, 1,603m, 1,646s, 1,694w, 3,082s. For far-FTIR spectra of 2, 2*, PABA@FeNPs and 2*@PABA@FeNPs see Supplementary Materials.

\section{Conclusions}

A simple approach was applied to obtain magnetic 4-aminobenzoic acid-coated maghemite nanoparticles with good stability in solution, with high magnetic response to the external magnetic field and showing superparamagnetic behaviour as proved by the Mössbauer spectroscopy experiments at room temperature. The systems were designed to be able to bind highly cytotoxic platinum(II) complexes involving 7-azaindole derivatives represented by the diaquaplatinum(II) species $\mathbf{1 *}$ and 2 * prepared by a $\operatorname{Ag}(\mathrm{I})$ ion-assisted activation from the initial highly cytotoxic dichlorido complexes. The incorporation of the platinum(II) species was proved by relevant techniques (FTIR, EDS), while a combination of the microscopic techniques (SEM, TEM) showed the obtained core-shell nanocomposites as having the spherical shape and an average size of $13 \mathrm{~nm}$ in diameter. Although we are aware of the fact that other important properties of the reported systems (e.g., release of the 
complex, in vitro cytotoxicity, in vitro toxicity or MRI experiments), should by also elucidated (the results will be a subject of our forthcoming studies), we have reason to believe that the prepared systems fulfil the basic requirements (magnetism, size, dispersibility or functionalization with therapeutically active substance) for the nanoparticles used in the field of theranostic nanomedicine.

\section{Supplementary Materials}

Supplementary materials can be accessed at: http://www.mdpi.com/19/2/1622/s1.

\section{Acknowledgments}

The authors gratefully thank the Czech Science Foundation (GAČRP207/11/0841), Operational Program Research and Development for Innovations-European Regional Development Fund (CZ.1.05/2.1.00/03.0058), Operational Program Education for Competitiveness-European Social Fund (CZ.1.07/2.3.00/20.0017) of the Ministry of Education, Youth and Sports of the Czech Republic and Palacký University in Olomouc (PrF_2013_015). The authors would like to thank Jana Gáliková and Klára Šafářová for performing FTIR, and TEM and SEM experiments, respectively.

\section{Author Contributions}

Conceived and designed the experiments: PŠ, ZT. Performed the experiments: MS, PŠ, JT. Analyzed the data: PŠ, JT, ZT. Wrote the paper: PŠ, JT, ZT.

\section{Conflicts of Interest}

The authors declare no conflict of interest.

\section{References}

1. Kelland, L. The resurgence of platinum-based cancer chemotherapy. Nat. Rev. Cancer 2007, 7, 573-584.

2. Butler, J.S.; Sadler, P.J. Targeted delivery of platinum-based anticancer complexes. Curr. Opin. Chem. Biol. 2013, 17, 175-188.

3. Zhang, Y.; Chan, H.F.; Leong, K.W. Advanced materials and processing for drug delivery: The past and the future. Adv. Drug Deliv. Rev. 2013, 65, 104-120.

4. Goncalves, A.S.; Macedo, A.S.; Souto, E.B. Therapeutic nanosystems for oncology nanomedicine. Clin. Transl. Oncol. 2012, 14, 883-890.

5. Chomoucka, J.; Drbohlavova, J.; Huska, D.; Adam, V.; Kizek, R.; Hubalek, J. Magnetic nanoparticles and targeted drug delivering. Pharmacol. Res. 2010, 62, 144-149.

6. Kievit, F.M.; Zhang, M. Surface Engineering of iron oxide nanoparticles for targeted cancer therapy. Acc. Chem. Res. 2011, 44, 853-862.

7. Gupta, A.K.; Gupta, M. Synthesis and surface engineering of iron oxide nanoparticles for biomedical applications. Biomaterials 2005, 26, 3995-4021. 
8. Laurent, S.; Forge, D.; Port, M.; Roch, A.; Robic, C.; Elst, L.V.; Muller, R.N. Magnetic iron oxide nanoparticles: Synthesis, Stabilization, Vectorization, Physicochemical characterizations, and biological applications. Chem. Rev. 2008, 108, 2064-2110.

9. Kelkar, S.S.; Reineke, T.M. Theranostics: Combining Imaging and Therapy. Bioconjugate. Chem. 2011, 22, 1879-1903.

10. Wang, N.; Guan, Y.; Yang, L.; Jia, L.; Wei, X.; Liu, H.; Guo, G. Magnetic nanoparticles (MNPs) covalently coated by PEO-PPO-PEO block copolymer for drug delivery. J. Colloid Interface Sci. 2013, 395, 50-57.

11. Nowicka, A.M.; Kowalczyk, A.; Jarzebinska, A.; Donten, M.; Krysinski, P.; Stojek, Z. Progress in targeting tumor cells by using drug-magnetic nanoparticles conjugate. Biomacromolecules 2013, 14, 828-833.

12. Karsten, S.; Nan, A.; Turcu, R.; Liebscher, J. A new access to polypyrrole-based functionalized magnetic core-shell nanoparticles. J. Polym. Sci. Part. A Polym. Chem. 2012, 50, 3986-3995.

13. Fan, C.H.; Ting, C.Y.; Lin, H.J.; Wang, C.H.; Liu, H.L.; Yen, T.C.; Yeh, C.K. SPIO-conjugated, doxorubicin-loaded microbubbles for concurrent MRI and focused-ultrasound enhanced brain-tumor drug delivery. Biomaterials 2013, 34, 3706-3715.

14. Gautiera, J.; Munniera, E.; Paillard, A.; Hervéa, K.; Douziech-Eyrollesa, L.; Soucé, M.; Duboisa, P.; Chourpa, I. A pharmaceutical study of doxorubicin-loaded PEGylated nanoparticles for magnetic drug targeting. Int. J. Pharm. 2012, 423, 16-25.

15. Kim, J.E.; Shin, J.Y.; Cho, M.H. Magnetic nanoparticles: An update of application for drug delivery and possible toxic effects. Arch. Toxicol. 2012, 86, 685-700.

16. Qi, L.; Wu, L.; Zheng, S.; Wang, Y.; Fu, H.; Cui, D. Cell-Penetrating Magnetic Nanoparticles for Highly Efficient Delivery and Intracellular Imaging of siRNA. Biomacromolecules 2012, 13, 2723-2730.

17. Huang, P.; Li, Z.; Lin, J.; Yang, D.; Gao, G.; Xu, C.; Bao, L.; Zhang, C.; Wang, K.; Song, H.; et al. Photosensitizer-conjugated magnetic nanoparticles for in vivo simultaneous magnetofluorescent imaging and targeting therapy. Biomaterials 2011, 32, 3447-3458.

18. Pan, B.; Cui, D.; Sheng, Y.; Ozkan C.; Gao, F.; He, R.; Li, Q.; Xu, P.; Huang, T. Dendrimer-modified magnetic nanoparticles enhance efficiency of gene delivery system. Cancer Res. 2007, 67, 8156-8163.

19. Knezevic, N.Z.; Ruiz-Hernandez, E.; Hennink, W.E.; Vallet-Regi, M. Magnetic mesoporous silica-based core/shell nanoparticles for biomedical applications. RSC Adv. 2013, 3, 9584-9593.

20. Wang, J.; Wang, X.; Song, Y.; Wang, J.; Zhang, C.; Chang, C.; Yan, J.; Qiu, L.; Wua, M.; Guo, Z. A platinum anticancer theranostic agent with magnetic targeting potential derived from maghemite nanoparticles. Chem. Sci. 2013, 4, 2605-2612.

21. Wang, J.; Wang, X.; Song, Y.; Zhu, C.; Wang, J.; Wang, K.; Guo, Z. Detecting and delivering platinum anticancer drugs using fluorescent maghemite nanoparticles. Chem. Commun. 2013, 49, 2786-2788.

22. Deng, H.; Lei, Z. Preparation and characterization of hollow $\mathrm{Fe}_{3} \mathrm{O}_{4} / \mathrm{SiO}_{2} @ \mathrm{PEG}-\mathrm{PLA}$ nanoparticles for drug delivery. Composites Part. B 2013, 54, 194-199.

23. Devi, S.V.; Prakash, T. Kinetics of cisplatin release by in-vitro using poly(D,L-Lactide) coated $\mathrm{Fe}_{3} \mathrm{O}_{4}$ nanocarriers. IEEE Trans. Nanobiosci. 2013, 12, 60-63. 
24. Ashjari, M.; Khoee, S.; Mahdavian, A.R. Controlling the morphology and surface property of magnetic/cisplatin-loaded nanocapsules via W/O/W double emulsion method. Colloids Surf. A Physicochem. Eng. Asp. 2012, 408, 87-96.

25. Xie, M.; Xu, Y.; Liu, J.; Zhang, T.; Zhang, H. Preparation and characterization of Folate targeting magnetic nanomedicine loaded with cisplatin. J. Nanomater. 2012, 2012, 921034.

26. Arias, J.L.; Reddy, L.H.; Othman, M.; Gillet, B.; Desmaele, D.; Zouhiri, F.; Dosio, F.; Gref, R.; Couvreur, P. Squalene based nanocomposites: A new platform for the design of multifunctional pharmaceutical theragnostics. ACS Nano. 2011, 5, 1513-1521.

27. Xing, R.; Wang, X.; Zhang, C.; Wang, J.; Zhang, Y.; Song, Y.; Guo, Z. Superparamagnetic magnetite nanocrystal clusters as potential magnetic carriers for the delivery of platinum anticancer drugs. J. Mater. Chem. 2011, 21, 11142-11149.

28. Sonoda, A.; Nitta, N.; Nitta-Seko, A.; Ohta, S.; Takamatsu, S.; Ikehata, Y.; Nagano, I.; Jo, J.; Tabata, Y.; Takahashi, M.; et al. Complex comprised of dextran magnetite and conjugated cisplatin exhibiting selective hyperthermic and controlled-release potential. Int. J. Nanomed. 2010, 5, 499-504.

29. Yang, J.; Lee, H.; Hyung, W.; Park, S.B.; Haam, S. Magnetic PECA nanoparticles as drug carriers for targeted delivery: Synthesis and release characteristics. J. Microencapsul. 2006, 23, 203-212.

30. Li, K.; Chen, B.; Xu, L.; Feng, J.; Xia, G.; Cheng, J.; Wang, J.; Gao, F.; Wang, X. Reversal of multidrug resistance by cisplatin-loaded magnetic $\mathrm{Fe}_{3} \mathrm{O}_{4}$ nanoparticles in A549/DDP lung cancer cells in vitro and in vivo. Int. J. Nanomed. 2013, 8, 1867-1877.

31. Zhang, Z.; Chai, A. Core-shell magnetite-silica composite nanoparticles enhancing DNA damage induced by a photoactive platinum-diimine complex in red light. J. Inor. Biochem. 2012, 117, 71-76.

32. Štarha, P.; Marek, J.; Trávníček, Z. Cisplatin and oxaliplatin derivatives involving 7-azaindole: Structural characterisations. Polyhedron 2012, 33, 104-409.

33. Štarha, P.; Trávníček, Z.; Popa, A.; Popa, I.; Muchová, T.; Brabec, V. How to modify 7-azaindole to form cytotoxic $\mathrm{Pt}(\mathrm{II})$ complexes: Highly in vitro anticancer effective cisplatin derivatives involving halogeno-substituted 7-azaindole J. Inorg. Biochem. 2012, 105, 57-63.

34. Muchová, T.; Prachařová, J.; Štarha, P.; Olivová, R.; Vrána, O.; Benešová, B.; Kašpárková, J.; Trávníček, Z.; Brabec, V. Insight into the toxic effects ofcis-dichloridoplatinum(II) complexes containing 7-azaindole halogeno derivatives in tumor cells. J. Biol. Inorg. Chem. 2013, 18, 579-589.

35. Maity, D.; Zoppellaro, G.; Sedenkova, V.; Tucek, J.; Safarova, K.; Polakova, K.; Tomankova, K.; Diwoky, C.; Stollberger, R.; Machala, L.; et al. Surface design of core-shell superparamagnetic iron oxide nanoparticles drives record relaxivity values in functional MRI contrast agents. Chem. Commun. 2012, 48, 11398-11400.

36. Hamoudeh, M.; Al Faraj, A.; Canet-Soulas, E.; Bessueille, F.; Leonard, D.; Fessi, H. Pharmaceutical nanotechnology elaboration of PLLA-based superparamagnetic nanoparticles: Characterization, magnetic behaviour study and in vitro relaxivity evaluation. Int. J. Pharm. 2007, $338,248-257$.

37. Dorniani, D.; Bin Hussein, M.Z.; Kura, A.U.; Fakurazi, S.; Shaari, A.H.; Ahmad, Z. Preparation of $\mathrm{Fe}_{3} \mathrm{O}_{4}$ magnetic nanoparticles coated with gallic acid for drug delivery. Int. J. Nanomed. 2012, 7, 5745-5756. 
38. Cafaggi, S.; Esposito, M.; Parodi, B.; Viale, M. A water-soluble 1,2-diaminocyclohexaneplatinum(II) complex containing procaine hydrochloride: Synthesis and antiproliferative activity in vitro. Pharmazie 1994, 49, 617-618.

39. Kukushkin, Y.N.; Blyumental, T.O.; Konovalov, L.V. Complex compounds of platinum(II) with p- and m-aminobenzoic acids. Zh. Obshch. Khim. 1979, 49, 1376-1379.

40. Rudyi, R.I.; Solomentseva, A.I.; Cherkashina, N.V.; Evstafeva, O.N.; Salyn, Y.V.; Moiseev, I.I. Complexes of platinum(II) and platinum(IV) with aromatic amines. Koord. Khim. 1976, 2, 499-506.

41. Davies, G.R.; Hewertson, W.; Mais, R.H.B.; Owston, P.G.; Patel, C.G. $\pi$-Complexes of platinum (II) with unsaturated hydrocarbons. Part II. Crystal and molecular structure of trans-dichloro-( $\pi$ di-t-butylacetyl-ene)-p-toluidineplatinum (II). J. Chem. Soc. A 1970, 1873-1877.

42. Rochon, F.D.; Bonnier, C. Study of Pt(II)-aromatic amines complexes of the types cis- and trans $-\mathrm{Pt}(\text { amine })_{2} \mathrm{I}_{2},\left[\mathrm{Pt}(\text { amine })_{4}\right] \mathrm{I}_{2}$ and $\mathrm{I}($ amine $) \mathrm{Pt}(\mu-\mathrm{I})_{2} \mathrm{Pt}($ amine $) \mathrm{I}$. Inorg. Chim. Acta 2007, 360, 461-472.

43. Karthikeyan, B. Density functional calculations on the structure, vibrational frequencies and normal modes of 7-Azaindole. Spectrochim. Acta 2006, A64, 1083-1087.

44. Ye, X.; Lin, D.; Jiao, Z.; Zhang, L. The thermal stability of nanocrystalline maghemite $\mathrm{Fe}_{2} \mathrm{O}_{3}$. J. Phys. D-Appl. Phys. 1998, 31, 2739-2744.

45. Cornell, R.M.; Schwertmann, U. The Iron Oxides: Structure, Properties, Reactions, Occurrence and Uses; Wiley-VCH Publishers: Weinheim, Germany, 2003.

46. Prochazka, R.; Tucek, P.; Tucek, J.; Marek, J.; Mashlan, M.; Pechousek, J. Statistical analysis and digital processing of the Mössbauer spectra. Meas. Sci. Technol. 2010, 21, 025107.

Sample Availability: Samples of the compounds 1, 2, 1*,2*,PABA@FeNPs, 1*PABA@FeNPs and 2*PABA@FeNPs are available from the authors.

(C) 2014 by the authors; licensee MDPI, Basel, Switzerland. This article is an open access article distributed under the terms and conditions of the Creative Commons Attribution license (http://creativecommons.org/licenses/by/3.0/). 